\title{
Low Response to the COVID-19 Vaccine Among the Arab Population in Israel: Is It a Cultural Background, or a Systemic Failure, or Maybe Both?
}

\author{
Ola Ali-Saleh ${ }^{1} \cdot$ Shiran Bord ${ }^{1} \cdot$ Fuad Basis $^{1,2,3}$ (B)
}

Received: 22 September 2021 / Revised: 1 December 2021 / Accepted: 17 December 2021/ Published online: 4 January 2022

(c) W. Montague Cobb-NMA Health Institute 2022

\begin{abstract}
Introduction A low response to COVID-19 vaccination was observed among the Arab population in Israel. Efforts to improve this achieved moderate results.

Objectives The aim of this study was to examine the extent to which demographic and cultural factors, the media, trust, perceptions, and government policies influence the willingness of Arabs to be vaccinated against COVID-19.

Methods A cross-sectional survey was conducted among Israeli Arabs (558 respondents). The questionnaire was distributed through social networks between January 16 and 26, 2021. The t-tests, Chi-square tests, Z tests, which were used to evaluate the significance of variables, and Pearson correlations calculated for the study variables were used for statistical analysis. Hierarchical logistic regression was calculated to assess the extent of background influence on the odds for vaccination, and mediation was examined using the Process procedure.

Results Moderate means were found for attitudes towards vaccination, vulnerability, vaccine effectiveness, and pandemic fatigue. A lower score was found for accessibility to medical services, social norms, and emotional barriers. Trust was highest in health-related authorities, whereas trust in government and the media was the lowest. Higher pandemic fatigue was associated with lower trust and lower odds for vaccination.

Discussion Lack of awareness of the specific needs of the Arab minority in Israel, lack of vaccination campaigns in Arabic language, long neglect of Arabs in the Israeli health system, mistrust of governmental authorities by the Arabs, and low socioeconomic background of Israeli Arabs might have led to lower trust levels and incompliance with governmental policies among Arabs. Addressing these issues may benefit the entire population. The authors believe that "A chain (in population health) is only as strong as its weakest link."
\end{abstract}

\section{Introduction}

At the time of writing this report (February 2021), there were 111,419,939 verified COVID-19 cases and 2,470,772 deaths from COVID-19 in 221 countries, where Israel had 742,752 verified cases and 5,522 deaths [1]. The rate of spread of the COVID-19 epidemic emphasized the importance of vaccine development, which is an effective means of protecting people from this disease and preventing illnesses [2]. The development of COVID-19 vaccines raises hope regarding our ability

Fuad Basis

f_basis@rmc.gov.il

1 The Max Stern Yezreel Valley College, Jezreel Valley, Israel

2 Technion Faculty of Medicine, Haifa, Israel

3 Rambam Health Care Campus, Haifa, Israel to fight the pandemic [3]. Nevertheless, a study examining the willingness to be vaccinated against COVID-19 before the vaccines became available found a reluctance to be vaccinated in different countries in the world [4]. Failure of some members of the public to be vaccinated may prevent reaching the immunization threshold required for herd immunity [5]. The factors associated with reluctance to be vaccinated can be understood through the Health Belief Model (HBM) [6, 7]. This model includes an individual's perception of the disease threat, their perception of the benefit in performing a behavior (vaccination), and their perception of the barriers to the behavioral change. In our context, these barriers may include the degree of transport accessibility to vaccination centers, the degree of linguistic accessibility, and the degree of accessibility of the vaccines (i.e., whether the vaccinations are carried out at the Health Maintenance Organizations (HMOs) centers in the villages or at central stations or hospitals in the main cities). 
Studies show that people who perceive their risks of contracting the disease as mild or low have low willingness to get vaccinated [8]. In addition, perceptions of the benefits of immunization have been found to be significant predictors of response to the vaccines [9]. Studies related to COVID19 vaccination have shown that mistrust of the benefits and safety of vaccines and concerns about their unintended effects are key barriers to willingness to be vaccinated [10, 11].

Furthermore, the factors that can lead to willingness to be vaccinated against COVID-19 can be understood using the Theory of Reasoned Action (TRA) [12]. The theory holds that an individual's decision to engage in a particular behavior is based on the outcomes the individual expects by performing the behavior [13]. Besides, a positive response to vaccination is related to some components of trust, viz.: trust in the product (the vaccine), trust in the supplier (the specific medical staff or administrative staff involved in administering the vaccine), and trust in policy makers (health systems, governments, public health researchers) [11, 14].

Wake et al., in a review of the literature, found that factors, such as educational status, income, race/ethnicity, social norms, perceived benefit of vaccination, perceived barriers to vaccination, perceived efficacy of the COVID19 vaccines, belief that vaccination makes one less worried about COVID-19, perceived potential harms due to the vaccines, belief that the vaccines can stop the pandemic, and having received any vaccine in the past 5 years, were associated with the willingness to receive the COVID-19 vaccines [15].

At the onset of a crisis like the COVID-19 pandemic, most people use mental and physical resources for shortterm survival in very stressful situations. However, as the difficult circumstances lengthen, they adopt a different coping mechanism, which may lead to "pandemic fatigue," and low motivation may prevail [16]. At the time of data collection for the current study, the world, including Israel, were in the midst of a third wave of pandemic. The morbidity rate in Israel is one of the highest in the world. To deal with the consequences of coronavirus infection and prevent its spread, the State of Israel, for the third time, ordered a lockdown from December 27, 2020, to January 9, 2021, which ensured remote, physical, and social isolation. However, it seems that there was little motivation to obey the precautionary rules, thus jeopardizing the ability to reduce the high rates of morbidity.

\section{Background}

The COVID-19 vaccination campaign began in Israel in December 2020 with the BNT162b2 vaccine developed by BioNTech and Pfizer 2020, continuing until March 2021. As at the time of writing this article, 5.2 million Israelis have been vaccinated, of which 4.3 million have received the second dose. In less than 2 months, over half of the population received at least one dose of the vaccine. Therefore, Israel continues to lead the rest of the world in the immunization rate [17].

Despite the progress in vaccination of all residents of Israel, the compliance with vaccination among the Arab population and Ultra-Orthodox Jews is lower compared to the rest of the population. The Arab population constitutes approximately $21.0 \%$ (1.916 million) of 9.1 million citizens in Israeli. Their household income and labor force participation are lower compared to the Jewish population. Housing is denser, with more than two persons sharing a room for $26.5 \%$ of Arab families' number, compared to $4.6 \%$ of the general Jewish population [18]. Moreover, the Arab population in Israel is also at an increased risk of morbidity and mortality from COVID-19, compared to the Jewish population, due to a higher incidence of risk factors and chronic diseases that increase the risk of mortality, such as diabetes, hypertension and cardiovascular diseases, smoking, obesity, and lack of physical activity [19].

Despite the success of the national vaccination campaign, the Arab population, according to data from the Ministry of Health, is at the bottom of the list of vaccinated segments, and in some predominantly Arab localities, the response to vaccination is nil. Reports from the Ministry of Health $(\mathrm{MOH})$ on February 1, 2021, showed that approximately $32 \%$ of the total population of Israel had received their first vaccination dose, compared to $18 \%$ among the Arab section. In addition, $81 \%$ of the total population in Israel over the age of $60 \mathrm{had}$ received the first dose of the vaccine, compared to 57\% among the Arab population [20]. With these findings, the need arose to examine the reason for the gap in compliance among Arabs with the instructions of the $\mathrm{MOH}$ and experts.

\section{Objectives}

The aim of this study was to examine the extent to which demographic and cultural factors, the media, trust, perceptions, and governmental policies influence the willingness of Arabs to be vaccinated against COVID-19.

\section{Materials and Methods}

\section{Survey Development}

The study was a cross-sectional survey that included 558 respondents from the Arab population in Israel. It was carried out between January 16 and 26, 2021, during the third 
lockdown period. The research questionnaire was partly based on validated questionnaires used in previous studies [21]. The questions were adapted and modified for the purpose of the present study. The questions related to the perception of the disease threat, barriers to vaccination, effectiveness perception, and incentives for action were based on the HBM model [6]. The questions that examined subjective attitudes and norms were compiled according to the Theory of Reasoned Action (TRA) [12]. To ensure the reliability of the questionnaire, Arabic and English language experts translated the items from the English language to Arabic and back to English. The variable COVID-19 consisted of two parts: the first, "Perceived susceptibility," included three items, such as "There is a high chance that I will have corona", and the second, "Perceived severity," included three statements, such as "Corona disease is dangerous and can cause suffering and serious complications and even death." In the context of "Perceived Barriers" (the third section), 10 items were added, for example: "I am afraid to try a vaccine that has not been tried by others for a whole year" or "I am afraid that the vaccine might have been developed quickly without information about vaccine safety and quality control." Five items were added to test the "Perceived benefits" of the vaccine, for example: "A vaccine against corona will allow us to return to normal life soon" or "A vaccine against corona will allow us to return soon to attending and holding weddings, prayers, religious ceremonies and funerals." Subjective norms and attitudes were assessed using questionnaires adapted from Ajzen et al [12, 22]. Subjective norms were assessed by 6 items, for example: "Many of my family members believe it is important to get vaccinated against corona." Attitudes towards the corona vaccine were also assessed using six items, for example: "I believe that a corona vaccine can one to get corona, natural immunity is preferable to me."

The questionnaire included 18 parameters that examined trust in formal and informal factors, such as (1) trust in personalities and formalities leading the way in dealing with COVID-19 in the State of Israel, e.g., the Prime Minister, Corona Projector, and Ministry of Health; (2) trust in informal factors, e.g., the clergy, friends, and family members; (3) trust in information obtained from the formal media (newspapers, news); and (4) trust in information obtained from the informal media such as various social networks. Respondents were asked to rate their response on a scale of 1 (not at all) to 5 (to a very large extent). Regarding pandemic fatigue, 8 statements were compiled based on the WHO2020 recommendations for formulating policies that would help countries deal with pandemic fatigue [23]. For samples of the study variables and internal consistencies and the Cronbach $\alpha$, see Table 1 .

The sample size was calculated with G*Power 3. For logistic regression with an odds ratio of 1.35 , two-sided analyses with $\alpha=0.05$ and power $=0.80$, the required sample size was 553 participants. For bivariate two-sided correlation analysis with a critical coefficient $r= \pm 0.08$ and power $=0.80$, the required sample size was 542 participants [24].

\section{Data Collection and Management}

The survey questionnaires were distributed, using the snowball method, through social networks such as Facebook and WhatsApp, and participants were asked to pass the link to the questionnaire to family members and other friends over the age of 18 years. Participants were asked to provide the following demographic details about themselves: age, gender, religion (Muslim, Bedouin, Druze, or Christian), degree of religiosity (secular, traditional, religious, or very religious), marital status, number of children, place of residence (North, Southern, or Central Israel), education (high school, post-secondary, academic education), type of employment (self-employed, employee, or unemployed), and income level.

\section{Data Analysis}

Data were analyzed with SPSS version 27. Internal consistencies were calculated for the study variables with Cronbach $\alpha$, and the variables were composed with the item means. Principal component exploratory factor analysis was performed for the items of trust, with the varimax rotation and eigenvalue greater than 1 . Demographic and background variables were described with means and standard deviations, or frequencies and percentages, and compared by vaccination with $t$-tests, Chi-square tests, and $Z$ tests for the significance of the difference between independent proportions. Means, standard deviations, and Pearson correlations were calculated for the study variables. Multiple hierarchical logistic regression was calculated to assess the extent to which the background variables and the study variables were related to the odds for vaccination. The background variables were entered in step 1 and the study variables in step 2. Mediation was examined with the Process procedure [25], using model 4 for a dichotomous-dependent variable and parallel mediation. Continuous variables were standardized, and 5000 bootstrap samples were used with a $95 \%$ confidence interval.

This study was approved by the Ethics Committee at the Yezreel Valley Academic College (Approval No: YVC EMEK 2021-25).

\section{Results}

The participants comprised of 558 Israeli Arab adult men $(22 \%)$ and women (78\%), with a mean age of about 40 years, most of whom were Muslim (91\%), married (72\%), 
Table 1 The study variables and internal consistencies

\begin{tabular}{|c|c|c|c|}
\hline Variable & $\begin{array}{l}\text { Number } \\
\text { of items }\end{array}$ & Example & Cronbach $\alpha$ \\
\hline Perceived susceptibility & 3 & "There is a high chance that I will have corona." & 0.82 \\
\hline Perceived severity & 3 & $\begin{array}{l}\text { "Corona disease is dangerous and can cause suffering and } \\
\text { serious complications and even death." }\end{array}$ & 0.78 \\
\hline Perceived barriers & 10 & $\begin{array}{l}\text { "I am afraid to try a vaccine that has not been tried by oth- } \\
\text { ers for a whole year." } \\
\text { "I am afraid that the vaccine will be developed quickly } \\
\text { without information about vaccine safety and quality } \\
\text { control." }\end{array}$ & 0.84 \\
\hline Perceived benefits of the vaccine/effectiveness & 5 & $\begin{array}{l}\text { "A vaccine against corona will allow us to return to normal } \\
\text { life soon." } \\
\text { "A vaccine against corona will allow us to return soon to } \\
\text { attend and hold weddings/prayers/religious ceremonies } \\
\text { and condolences." }\end{array}$ & 0.94 \\
\hline Subjective norms & 6 & $\begin{array}{l}\text { "Many of my family members believe it is important to get } \\
\text { vaccinated against corona." }\end{array}$ & 0.72 \\
\hline Attitudes towards the corona vaccine & 6 & $\begin{array}{l}\text { "I believe that a corona vaccine can cause a vaccinated per- } \\
\text { son to get corona, natural immunity is preferable to me." }\end{array}$ & 0.78 \\
\hline Trust in formal and informal factors & 18 & $\begin{array}{l}\text { "I trust the physicians." } \\
\text { "I trust the government." } \\
\text { "I trust social networks' information." }\end{array}$ & 0.89 \\
\hline Pandemic fatigue & 8 & $\begin{array}{l}\text { "I'm tired of following the guidelines." } \\
\text { "The State/Ministry of Health does not explain the logic } \\
\text { behind the guidelines." }\end{array}$ & 0.85 \\
\hline \multicolumn{4}{|l|}{ COVID-19 questions: } \\
\hline "Did you receive a recommendation for a corona vaccine." & 1 & & \\
\hline "Did you get sick in Corona." & 1 & & \\
\hline "Did your relative get sick in Corona." & 1 & & \\
\hline Vaccination status & 1 & & \\
\hline Demographic details & & $\begin{array}{l}\text { Age, gender, religion, degree of religiosity, marital status, } \\
\text { number of children, place of residence in Israel, level of } \\
\text { education, type of employment, income level }\end{array}$ & \\
\hline
\end{tabular}

and parents (73\%) (Table 2). Over $60 \%$ of the participants $(n=348,62.4 \%)$ reported that they were or would soon be vaccinated, while others $(n=210,37.6 \%)$ were hesitant or did not intend to get vaccinated.

Most participants had more than a high school education (81\%) and were employed $(66 \%)$. About $40 \%$ of participants were employed in the education system, and about $17 \%$ were employed in the health system $(1.8 \%, n=10$ reported working in both systems). Most participants lived in rural residences $(63 \%)$, and $73 \%$ lived in the northern part of Israel. Over a half (54\%) were religious, and about a third $(35 \%)$ were partly religious. Most reported a low (56\%) or an average $(31 \%)$ economic status.

Applying the Bonferroni criterion for multiple comparisons (Table 2, $p<0.004$ ), significant differences were found by vaccination (yes/no). Vaccination, or the intention to be vaccinated, was higher among males than females and among older than younger participants. It was higher among participants with an academic education than among participants with lower than an academic education and among employed than unemployed participants. Further, vaccination, or the intention to be vaccinated, was higher among participants working in the health system than among those working in other sectors and among those with an average or above average economic status than those with a low economic status.

Most participants reported a very good/excellent health status ( $n=417,74.7 \%$ ), while some others reported a moderate/reasonable health status $(n=125,22.4 \%)$. Only a few reported a bad health status ( $n=16,2.9 \%)$, and about a quarter were on medication for a chronic illness $(n=135,24.2 \%)$. About two-thirds of the participants reported that their significant other person was sick with COVID-19 ( $n=366$, $65.6 \%$ ), and almost all reported that the COVID-19 vaccine was recommended to them $(n=489,87.6 \%)$. It is interesting to note that the ill health of a family member was unrelated to vaccination $(Z=1.85, p=0.065)$.

Distributions in Table 3 reveal moderate means for most of the study variables, including attitudes towards vaccination, subjective norms, susceptibility, perceived severity, 
Table 2 Background characteristics by vaccination $(N=558)$

Socio-demographic characteristics

Total sample No intention/hesi- Vaccinated/

tation $(n=210) \quad$ intends to

$(n=348)$

\begin{tabular}{|c|c|c|c|c|}
\hline \multicolumn{5}{|l|}{ Gender $(\%)$} \\
\hline Male & $123(22.0)$ & $33(26.8)$ & $90(73.2)$ & \multirow{2}{*}{$\begin{array}{l}Z=\mathbf{2 . 8 0} \\
p=.005\end{array}$} \\
\hline Female & $435(78.0)$ & $177(40.7)$ & $258(59.3)$ & \\
\hline Mean age $(S D)$, range & $40.93(13.64), 18-74$ & $35.57(12.16)$ & $44.16(13.47)$ & $\begin{array}{l}t(556)=7.57 \\
p<.001\end{array}$ \\
\hline \multicolumn{5}{|l|}{ Religion (\%) } \\
\hline Moslem & $506(90.7)$ & $194(38.3)$ & $312(61.7)$ & \multirow{3}{*}{$\begin{array}{l}\chi^{2}(2)=2.09 \\
p=.351\end{array}$} \\
\hline Christian & $41(7.3)$ & $14(34.1)$ & $27(65.9)$ & \\
\hline Druze & $11(2.0)$ & $2(18.2)$ & $9(81.8)$ & \\
\hline \multicolumn{5}{|l|}{ Marital status (\%) } \\
\hline Married & $400(72.5)$ & $138(34.5)$ & $262(65.5)$ & \multirow{2}{*}{$\begin{array}{l}\chi^{2}(3)=8.35 \\
p=.039\end{array}$} \\
\hline Single & $152(27.5)$ & $72(49.1)$ & $57(50.9)$ & \\
\hline Children (yes) (\%) & $408(73.1)$ & $140(34.3)$ & $268(65.7)$ & $\begin{array}{l}Z=2.67 \\
p=.008\end{array}$ \\
\hline Mean number of children $(S D)$, range $(n=407)$ & $3.46(1.65), 1-9$ & $3.27(1.69)$ & $3.56(1.62)$ & $\begin{array}{l}t(405)=1.68 \\
p=.093\end{array}$ \\
\hline \multicolumn{5}{|l|}{ Education $(\%)$} \\
\hline Up to 8 years & $17(3.0)$ & $6(35.3)$ & $11(64.7)$ & \multirow{6}{*}{$\begin{array}{l}Z=2.60 \\
p=.009 \\
\text { (academic vs. non-academic) }\end{array}$} \\
\hline 8 to 12 years & $88(15.8)$ & $45(51.5)$ & $43(48.9)$ & \\
\hline Higher education & $81(14.5)$ & $33(40.7)$ & $48(59.3)$ & \\
\hline BA student & $75(13.4)$ & $42(56.0)$ & $33(44.0)$ & \\
\hline BA & $189(33.9)$ & $60(31.7)$ & $129(68.3)$ & \\
\hline MA and above & $108(19.4)$ & $24(22.2)$ & $84(77.8)$ & \\
\hline \multicolumn{5}{|l|}{ Employment (\%) } \\
\hline Employed & $368(66.0)$ & $109(29.6)$ & $259(70.4)$ & \multirow{2}{*}{$\begin{array}{l}Z=5.44 \\
p<.001 \\
\text { (employed vs. unemployed) }\end{array}$} \\
\hline Unemployed & $51(9.1)$ & $34(66.7)$ & $17(33.3)$ & \\
\hline \multicolumn{5}{|l|}{ Employment type (\%) } \\
\hline Employed in the health system & $95(17.0)$ & $19(20.0)$ & $76(80.0)$ & $\begin{array}{l}Z=3.90 \\
p<.001\end{array}$ \\
\hline Employed in the education system & $223(40.0)$ & $70(31.4)$ & $153(68.6)$ & $\begin{array}{l}Z=2.48 \\
p=.013\end{array}$ \\
\hline \multicolumn{5}{|l|}{ Area of residence $(\%)$} \\
\hline Urban & $208(37.3)$ & $75(36.1)$ & $133(63.9)$ & \multirow{2}{*}{$\begin{array}{l}Z=0.59 \\
p=.553\end{array}$} \\
\hline Rural & $350(62.7)$ & $135(38.6)$ & $215(61.4)$ & \\
\hline \multicolumn{5}{|l|}{ Level of religiosity (\%) } \\
\hline Secular & $61(10.9)$ & $28(45.9)$ & $33(54.1)$ & \multirow{4}{*}{$\begin{array}{l}\chi^{2}(3)=1.41 \\
p=.158\end{array}$} \\
\hline Partly religious & $193(34.6)$ & $70(36.3)$ & $123(63.7)$ & \\
\hline Religious & $275(49.3)$ & $103(37.5)$ & $172(62.5)$ & \\
\hline Orthodox & $29(5.2)$ & $9(31.0)$ & $20(69.0)$ & \\
\hline \multicolumn{5}{|l|}{ Economic status $(\%)$} \\
\hline Below average & $303(56.4)$ & $126(41.6)$ & $177(58.4)$ & \multirow{3}{*}{$\begin{array}{l}\chi^{2}(2)=11.40 \\
p=.003\end{array}$} \\
\hline About average & $169(31.5)$ & $44(26.0)$ & $125(74.0)$ & \\
\hline Above average & $65(12.1)$ & $23(35.4)$ & $42(64.6)$ & \\
\hline
\end{tabular}

effectiveness, trust, and pandemic fatigue. A low average score was found for barriers. The total trust score was moderate, yet its components revealed a more complex picture.
Trust regarding COVID-19 issues was highest in formal and non-formal health-related authorities $(M=3.60, S D=1.04)$; higher in governmental, municipal, and religious authorities 
Table 3 Means, standard deviations, and correlations for the study variables $(N=558)$

\begin{tabular}{|c|c|c|c|c|c|c|c|c|c|}
\hline & $M(S D)$ & 2 & 3 & 4 & 5 & 6 & 7 & 8 & 9 \\
\hline 1. Vaccinated & $0.62(0.48)$ & $.59 *$ & $.42 *$ & .07 & $.36^{*}$ & $-.48^{*}$ & $.55^{*}$ & $.34^{*}$ & $-.25^{*}$ \\
\hline 2. Attitudes & $3.78(0.93)$ & & $.35^{*}$ & .03 & $.54 *$ & $-.57 *$ & $.65^{*}$ & $.28^{*}$ & $-.26^{*}$ \\
\hline 3. Subjective norms & $3.39(0.77)$ & & & .09 & $.34 *$ & $-.42 *$ & $.43 *$ & $.38^{*}$ & $-.29 *$ \\
\hline 4. Susceptibility & $3.30(1.12)$ & & & & $.16^{*}$ & .12 & $.18^{*}$ & .11 & .03 \\
\hline 5. Severity & $3.76(1.02)$ & & & & & $-.28^{*}$ & $.53^{*}$ & $.27 *$ & $-.20 *$ \\
\hline 6. Barriers & $2.64(0.85)$ & & & & & & $-.38^{*}$ & $-.20^{*}$ & $.34 *$ \\
\hline 7. Effectiveness & $3.82(1.10)$ & & & & & & & $.39 *$ & $-.20 *$ \\
\hline 8.Trust-total score & $2.89(0.84)$ & & & & & & & & $-.50 *$ \\
\hline 9. Pandemic fatigue & $3.26(0.95)$ & & & & & & & & \\
\hline
\end{tabular}

$(M=2.76, S D=1.07)$; and lowest in non-formal support, and the media $(M=2.21, S D=0.98)(F(2,1114)=436.30$, $\left.p<0.001, \eta^{2}=0.439\right)$.

Applying the Bonferroni criterion for multiple comparisons $(p<0.001)$, most correlations presented in Table 3 were found to be significant. Vaccination, or the intention to be vaccinated, was positively related between every two of attitudes towards vaccination and subjective norms, perceived severity, effectiveness, and trust. However, it was negatively related to both barriers to vaccination and pandemic fatigue and unrelated to susceptibility. It is interesting to note that susceptibility was generally unrelated to the other study variables.

Results presented in Table 2 show that gender, age, education level, employment status, and economic status were the main demographic/socioeconomic characteristics related to vaccination or the intention to be vaccinated. Economic status was found to be related to employment status, as most unemployed participants reported below-average income ( $n=122,72.2 \%$ of 169), compared to about a half of the employed ones $(n=188,49.2 \%$ of 368$)\left(\chi^{2}(2)=31.34\right.$, $p<0.001)$. Thus, in light of the significant differences shown in Table 2 and the relationship between employment and economic status, the control variables used for further analyses were gender ( 1 , male; 0 , female), age, education level ( 1 , academic; 0 , non-academic), and employment status (1, employed; 0, unemployed).

Multiple hierarchical logistic regression was calculated to assess the extent to which the background variables and the study variables (attitudes towards vaccination, subjective norms, susceptibility, perceived severity, barriers to vaccination, effectiveness, trust, and pandemic fatigue) were related to the odds for vaccination (Table 4). The resulting model was found to be significant, with about $61 \%$ of the variance in the odds for vaccination explained by it. For the background characteristics, age and employment status were significant, with older participants and employed participants showing higher odds for vaccination. Furthermore, positive attitudes towards vaccination, supportive subjective norms, greater perceived effectiveness, higher level of trust, and lower barriers to vaccination were associated with higher odds for vaccination.

To assess the extent to which trust and barriers mediated the relationship between pandemic fatigue and vaccination, a process model [25] was designed, using model 4 for a dichotomous dependent variable with parallel mediation. Continuous variables were standardized, and the control variables were gender, age, education level, and employment status (Fig. 1). The total indirect effect was found to be significant (effect $=-0.84, S E=0.12,95 \% \mathrm{CI}:-1.11,-0.66$ ), as well as the individual indirect effects (trust: effect $=-0.48$, $S E=0.09,95 \%$ CI: $-0.67,-0.33$; barriers: effect $=-0.37$, $S E=0.07,95 \% \mathrm{CI}:-0.52,-0.26)$. This implies that higher pandemic fatigue was related to lower trust and higher barriers, which were related to lower odds for vaccination.

\section{Discussion}

In our study, $91 \%$ of the respondents were Muslims. The percentage of Israeli Arabs that are Muslim is about 96\% [26]. Most participants had more than a high school education (81\%). Although the rate of vaccination among the elderly Arab population (above 65 years) was lower than that among the same age in the general population (57\% vs. $82 \%$ ), the willingness and compliance to be vaccinated was still higher among this age group compared to the younger Arab generation. This might be a pointer that the way we distributed the questionnaire did not bias the total results towards a negative trend. The $\mathrm{MOH}$ campaign that highlighted the high mortality rate among the elderly population might have led the high rate of population among them. The low rate of vaccination among the elderly Arab population, compared to the elderly in the general population, could be explained partially by physical boundaries that made the vaccine inaccessible to the Arab population in their residential areas (see below).

In our study, $78 \%$ of the respondents were women. Some studies have shown that women tend to use social networking 
Table 4 Multiple hierarchical logistic regression for vaccination $(N=558)$

\begin{tabular}{llll}
\hline & $B(S E)$ & $O R(95 \% C I)$ & $p$ \\
\hline Step 1 & & & \\
\hline Gender (male) & $0.40(0.24)$ & $1.49(0.93,2.40)$ & .098 \\
Age & $0.05(0.01)$ & $1.05(1.03,1.06)$ & $<.001$ \\
Education level (academic) & $0.33(0.20)$ & $1.39(0.93,2.06)$ & .108 \\
Employment status (employed) & $0.78(0.20)$ & $2.18(1.46,3.23)$ & $<.001$ \\
Step 2 & & & \\
Gender (male) & $-0.04(0.33)$ & $0.96(0.50,1.84)$ & .906 \\
Age & $0.04(0.01)$ & $1.04(1.02,1.06)$ & $<.001$ \\
Education level (academic) & $0.16(0.28)$ & $1.17(0.68,2.03)$ & .566 \\
Employment status (employed) & $0.77(0.28)$ & $2.16(1.26,3.72)$ & .005 \\
Attitudes & $0.94(0.20)$ & $2.57(1.73,3.81)$ & $<.001$ \\
Subjective norms & $0.47(0.21)$ & $1.60(1.07,2.40)$ & .022 \\
Susceptibility & $0.11(0.12)$ & $1.11(0.87,1.42)$ & .391 \\
Severity & $0.07(0.14)$ & $1.08(0.82,1.42)$ & .600 \\
Barriers & $-0.72(0.20)$ & $0.49(0.33,0.73)$ & $<.001$ \\
Effectiveness & $0.52(0.16)$ & $1.68(1.24,2.29)$ & $<.001$ \\
Trust-total score & $0.67(0.21)$ & $1.95(1.31,2.92)$ & .001 \\
Pandemic fatigue & $-0.23(0.15)$ & $0.79(0.59,1.07)$ & .128 \\
\hline
\end{tabular}

Step 1: $\chi^{2}(4)=79.68, p<.001$, Nagelkerke's $R^{2}=.181$

Step 2: $\chi^{2}(8)=255.21, p<.001$, Nagelkerke's $\Delta R^{2}=.434$

Total model: $\chi^{2}(12)=334.89, p<.001$, Nagelkerke's $R^{2}=.615$

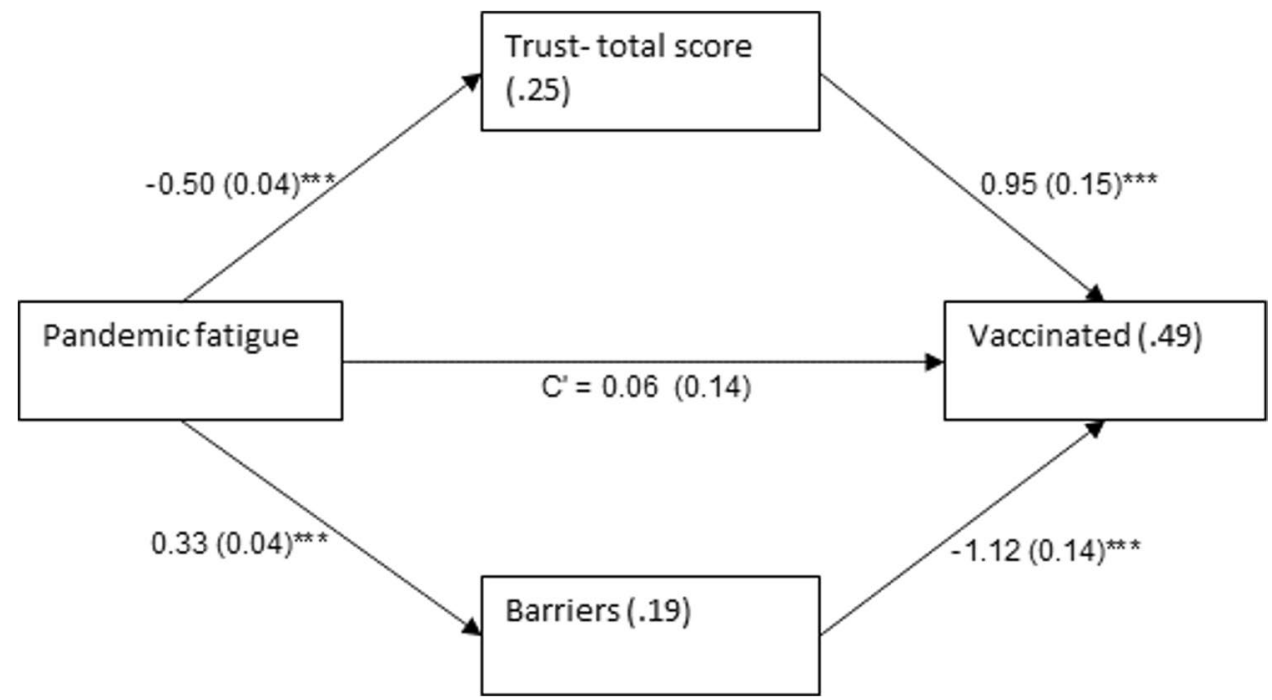

Fig. 1 Process model for trust and barriers as mediators between pandemic fatigue and vaccination. Note: Values on arrows: $B(S E)$, values within rectangles: $R^{2}, \mathrm{C}^{\prime}=$ direct effect. $* * * p<.001$ services (SNS) more than men [27, 28]. In their study, Araz et al. showed that in the early stages of the COVID-19 epidemic, the level of panic among people who used SNS was significantly higher compared to those who did not [29]. This may in part explain the high rate of skepticism among females compared to males in their attitudes towards the vaccine $(40.7 \%$ vs $26.8 \%$ ) (Table 2$)$. The vaccination rate was higher among the employed compared with the unemployed population $(p<0.001)$. This might be because the employed hoped to return to work once they get vaccinated.
Barriers to reaching the vaccination centers were found to be of significant importance in making the vaccine accessible to residents. At the start of vaccination, vaccination stations were available only in hospitals. Only later, when it was found that the response to vaccination in the rural areas was low, did the HMOs set out to specifically vaccinate the rural populations, reaching the Arab villages at a later stage [30]. A similar finding was described by Abdul-Mutakabbir et al., who found a low vaccination rate among blacks in the USA due to lack of accessibility to vaccination centers 
and hence a higher mortality rate [31]. The vaccine reached the Arab villages with considerable delay, and some believe this is a failure of the system with regard to the provision of health services to this population and a result of the inequalities in healthcare provisions between Arabs and Jews in Israel [32].

Although the socioeconomic status of Arabs in Israel has shown some improvement in recent years, there are still significant gaps between the conditions of the Arabs and the Jews. The gaps between the Arab and Jewish populations in Israel stem from pre-labor market barriers to investment in human capital, such as discrimination, low level of transportation/infrastructure, shortage of accessible employment areas, barriers to market entry, and weakness of Arab local authorities [33]. Low socioeconomic status is well correlated with low compliance to vaccination, which coincides with the findings of Daoud et al. and others about the influence of social, educational, and material conditions of the Arab minority in Israel on their low health awareness [32]. The Arab population suffered years of discrimination before the development of health infrastructure in their areas, less investment in their socioeconomic background, and poor awareness of the benefits of higher education [34].

Furthermore, during the first outbreak of the coronavirus, Israel was in the middle of a complicated political situation. There was a second round of elections, no stable government, and a campaign against the Arab segment of the population by some politicians to gain more votes from the Jewish fanatic segment. This campaign began 2 years earlier when the "Nationality Law" was enacted by the previous government, decreeing that Israel was the state of the Jews. Israeli Arabs are considered legal citizens of the state, while Arabs outside Israel (Palestinians, for example), who marry Israeli Arabs, are not considered Israeli citizens and have no right to vote in elections. This might have hurt the Arabs' trust in government authorities, leading to significantly lower response to COVID-19 vaccination and a higher trust in professional authorities. There were some disagreements between the professional and political leadership, which might have contributed to the Arabs' mistrust in the whole system [35]. Trust in the vaccines is very important and critically dependent on the ability of governments to communicate the benefits of vaccination and to deliver the vaccines safely and effectively [14]. In our study, trust regarding COVID-19 issues was highest in health-related authorities; higher in governmental, municipal, and religious authorities; and lowest in non-formal support and the media. Trust in the SNS media was low because of the many fake news spread through it. This finding is consistent with that of Moscadelli et al.'s large systematic review of articles on fake news [36]. Furthermore, the current epidemic, compared to its predecessors such as the H1N1 of 2008, has been characterized by high involvement of the SNS and dissemination of fake news, which have affected public trust in the vaccines even in other countries [37]. It should be emphasized that, in our study, trust in itself predicted immunization (according to the regression model) but also constituted an important mediating variable between pandemic fatigue and immunization.

Another point to consider is that the MOH did not conduct an explanatory campaign in the Arabic language backed up by public figures, as it did for the Jewish population. This discrimination became clear to decision-makers relatively late. After an intensive campaign, there was a rise in the vaccination rate among Arabs, although this remained lower than the rate among the general population.

Social norms (i.e., whether people valued by an individual support getting a vaccine) and perceived behavioral control (i.e., whether the ability to get the vaccine is within an individual's control) are positively related to willingness to get vaccinated [38]. The Theory of Planned Behavior (TPB) suggests that behavior is driven by intention to carry out the behavior, which in turn is determined by attitudes towards the behavior, for example, getting a COVID-19 vaccine (i.e., its perceived benefit, value, and positivity), and social norms. As mentioned above, the $\mathrm{MOH}$ and the Israeli government did not launch an explanatory campaign in Arabic nor did they employ the support of key and influential Arabs, as they did with the Jews.

Considering that there have been three lockdowns and over a year of restrictions in Israel, our study results show that higher pandemic fatigue was associated with lower trust and higher barriers to vaccination, which were in turn associated with lower odds for vaccination (see Fig. 1). Pandemic fatigue is the feeling just being tired of the pandemic and of keeping the safety precautions. More and more people skip wearing masks, attend small and even large gatherings, and generally break the rules. This feeling may explain in a way the resistance to vaccination, as people get used to or oversaturated with sick people and deaths [39].

According to Badre et al., a neuroscientist, life during the pandemic has been full of tasks that require mental effort, and so mental exhaustion is not surprising. We are constantly adjusting to new rules and policies that require cognitive control to plan and monitor every step of the way. Changes in the perceived value of these behaviors will make those efforts harder to tolerate for long periods, and compliance will decline. Therefore, addressing pandemic fatigue requires a robust and multipronged response that focuses not only on the political and social aspects but also on motivation in terms of costs and benefits of mitigation behaviors. Economic relief is needed because it addresses this opportunity cost of compliance. Our willingness to invest mental effort in a task is dependent on our belief in the efficacy of doing so. Misinformation is rampant, and there was a lack of consistent guidance from the political leadership about what effective 
actions to take. Once an effective set of rules are in place, we need those rules to be as stable as possible. Thus, even if there was bound to be pandemic fatigue at some point, it seems that higher levels of confidence could have regulated the effect of fatigue on the population's responsiveness [40].

\section{Limitations of the Study}

This research used a questionnaire distributed in a rolling method through social networks. To some extent, this might have created some bias in relation to the segment of the population that does not use social networks. It might have been better to distribute a questionnaire personally, according to the percentage of age groups in the population, although this would have been very difficult. The older population, who are not very active on social networks, were more open to receiving the vaccine. The reason for this is worth considering in future studies.

Furthermore, the connection between the political situation in the country and the trust of the Arab population in the government in relation to the reliability of the vaccines should be further examined in future studies.

In conclusion, the authors believe that investing in infrastructure and health education and improving the socioeconomic background of ethnic and minority groups may save unnecessary health expenditure and improve the welfare of the entire population, especially when a contagious disease is concerned. A chain is only as strong as its weakest link. The government should put in more effort to address this issue of discrimination against Arabs in Israel's health system. The authors recommend that, beyond public health, the political authorities and decision-makers should consider this point also in the context of other issues.

\section{References}

1. World Health Organization. WHO coronavirus (COVID-19) dashboard. At: https://covid19.who.int/region/euro/country/il. Retrieved Feb 2021. 2020

2. Yang P, Wang X. COVID-19: a new challenge for human beings. Cell Mol Immunol. 2020;17(5):555-7.

3. Haynes BF. A new vaccine to battle Covid-19. N Engl J Med. 2021;384(5):470-471. https://doi.org/10.1056/NEJMe2035557.

4. Neumann-Böhme S, Varghese NE, Sabat I, Barros PP, Brouwer W, van Exel J, Schreyögg J, Stargardt T. Once we have it, will we use it? A European survey on willingness to bevaccinated against COVID-19. Eur J Health Econ. 2020;21(7):977-982. https://doi. org/10.1007/s10198-020-01208-6.

5. Fontanet A, Cauchemez S. COVID-19 herd immunity: where are we? Nat Rev Immunol. 2020;20(10):583-4.

6. Smith PJ, Humiston SG, Marcuse EK, Zhao Z, Hibbs B, et al. Parental delay or refusal of vaccine doses, childhood vaccination coverage at 24 months of age, and the Health Belief Model. Public Health Rep. 2011;126(2_suppl):135-46.
7. Rosenstock IM. The Health Belief Model and preventive health behavior. Health education monographs. 1974; 2(4), 354-386. at: https://doi.org/10.1177/109019817400200405. Retrieved Feb 2021.

8. Baumgaertner B, Ridenhour BJ, Justwan F, Carlisle JE, Miller CR. Risk of disease and willingness to vaccinate in the United States: A population-based survey. PLoS Med. 2020;17(10):e1003354. https://doi.org/10.1371/journal.pmed.1003354

9. Fazekas KI, Brewer NT, Smith JS. HPV vaccine acceptability in a rural southern area. J Womens Health. 2008;17(4):539-48.

10. Paul E, Steptoe A, Fancourt D. Attitudes towards vaccines and intention to vaccinate against COVID-19: implications for public health communications. Lancet Reg Health Eur. 2021;1:100012.

11. Satran C, Ali-Saleh O, Mashiach-Eizenberg M, Bord S. Stress and perceived discrimination among the Arab population in Israel: the mediation role of the perceived COVID-19 threat and trust in the healthcare system. Ethn Health. 2021;18:1-18. https://doi.org/10. 1080/13557858.2021.1899139.

12. Ajzen I, Fishbein M. Understanding attitudes and predicting social behavior. Englewood Cliffs: Prentice-Hall; 1980.

13. Chan M, Woon I, Kankanhalli A. Perceptions of information security in the workplace: linking information security climate to compliant behavior. J Inf Priv Secur. 2005;1(3):18-41.

14. Larson HJ, Schulz WS, Tucker JD, \& Smith DM. Measuring vaccine confidence: introducing a global vaccine confidence index. PLoS currents. 2015; 7.

15. Wake AD. The willingness to receive COVID-19 vaccine and its associated factors: "Vaccination Refusal Could Prolong the War of This Pandemic" - a systematic review. Risk Manag Healthc Policy. 2021;14:2609-23. https://doi.org/10.2147/RMHP.S311074.

16. Masten AS, Motti-Stefanidi F. Multisystem resilience for children and youth in disaster: reflections in the context of COVID-19. Adv Res Sci. 2020;1(2):95-106.

17. Garti E (MD): The scientific race to eradicate the corona. Weekly update. At: https://davidson.weizmann.ac.il/online/sciencenews/\% D7\%94\%D7\%9E\%D7\%99\%D7\%A8\%D7\%95\%D7\%A5-\%D7\% 94\%D7\%9E\%D7\%93\%D7\%A2\%D7\%99-\%D7\%9C\%D7\%9E\% D7\%99\%D7\%92\%D7\%95\%D7\%A8-\%D7\%94\%D7\%A7\%D7\% 95\%D7\%A8\%D7\%95\%D7\%A0\%D7\%94-\%D7\%A2\%D7\%93\% D7\%9B\%D7\%95\%D7\%9F-\%D7\%A9\%D7\%91\%D7\%95\%D7\% A2\%D7\%99. (Hebrew) Retrieved March 2021

18. Chernichovsky D, Bisharat B, Bowers L, Brill A, Sharony C (2017) The health of the Arab Israeli population. State of the nation report. At: https://www.taubcenter.org.il/wpcontent/uploads/2020/12/healt hofthearabisraelipopulation.pdf. Retrieved March 2021

19. Taub Center For Social Policy Studies In Israel. The singer series: state of the nation report 2017. AT: http://taubcenter.org.il/stateof-the-nation-report-2017/. Retrieved March 2021.

20. MOH: National trends in sectoral cross-section, at: https://www. israelhayom.co.il/sites/default/files/\%D7\%A0\%D7\%AA\%D7\% 95\%D7\%A0\%D7\%99\%20\%D7\%9E\%D7\%A9\%D7\%A8\%D7\%93\% 20\%D7\%94\%D7\%91\%D7\%A8\%D7\%99\%D7\%90\%D7\%95\%D7\% AA $\% 20-\% 20 \% \mathrm{D} 7 \% 9 \mathrm{E} \% \mathrm{D} 7 \% 93 \% \mathrm{D} 7 \% 93 \% \mathrm{D} 7 \% 99 \% \mathrm{D} 7 \% 9 \mathrm{D} \%$ 20\%D7\%9B\%D7\%9C\%D7\%9C\%D7\%99\%D7\%99\%D7\%9D\%20\% D7\%9E\%D7\%92\%D7\%96\%D7\%A8\%20\%D7\%97\%D7\%A8\%D7\% 93\%D7\%99.pdf Retrieved March 2021. (Hebrew)

21. Prasetyo YT, Castillo AM, Salonga LJ, Sia JA, Seneta JA. Factors affecting perceived effectiveness of COVID-19 prevention measures among Filipinos during enhanced community quarantine in Luzon, Philippines: integrating protection motivation theory and extended theory of planned behavior. Int J Infect Dis. 2020;99:312-23.

22. Ajzen I, Madden JT. Prediction of goal-directed behavior: attitudes, intentions, and perceived behavioral control. J Exp Soc Psychol. 1986;22(5):453-74.

23. WHO-Euro 2020: Pandemic fatigue reinvigorating the public to prevent COVID-19 at: https://apps.who.int/iris/bitstream/handle/ 
10665/335820/WHO-EURO-2020-1160-40906-55390-eng.pdf. Retrieved April 2021

24. Faul F, Erdfelder E, Lang A-G, Buchner A. G*Power 3: a flexible statistical power analysis program for the social, behavioral, and biomedical sciences. Behav Res Methods. 2007;39:175-91.

25. Hayes AF. Introduction to mediation, moderation, and conditional process analysis: a regression-based approach. New York: Guilford Press; 2018.

26. Israel Central Bureau of Statistics at: https://www.cbs.gov.il/he/ mediarelease/DocLib/2021/023/33_21_023b.pdf. Retrieved Feb $\underline{2021}$

27. Tufekci Z. Grooming, gossip, Facebook, and MySpace. Inf Commun Soc. 2008;11(4):544-64.

28. Hargittai E. Whose space? Differences among users and nonusers of social network sites. J Comput-Mediat Commun. 2007;13(1):276-97.

29. Araz RA, Hersh RM. The impact of social media on panic during the COVID-19 pandemic in Iraqi Kurdistan: online questionnaire study. J Med Internet Res. 2020;22(5):e19556.

30. Daoud N. In order for the Arab public to be vaccinated, it is important to make vaccines accessible at: https://www.globes. co.il/news/article.aspx?did=1001357824. Retrieved March 2021

31. Abdul-Mutakabbir JC, Casey S, Jews V, King A, Kelvin S, Hogue $\mathrm{M}$, et al. A three-tiered approach to address barriers to COVID19 vaccine delivery in the Black community. Lancet global Open Access Published: March10, 2021 at: https://www.thelancet. com/journals/langlo/article/PIIS2214-109X(21)00099-1/fulltext. Retrieved May 2021.

32. Daoud N, Soskolne V, Mindell JS, Roth MA, Manor O. Ethnic inequalities in health between Arabs and Jews in Israel: the relative contribution of individual-level factors and the living environment. Int J Public Health. 2018;63(3):313-23. https://doi.org/10. 1007/s00038-017-1065-3.

33. Eran Yeshiv and Nitza Kleiner (Kassir). The economy of Arab Society in Israel; In the book "Lights and Shadows in the Market Economy - The Israeli Economy 1995-2015," Falk Institute \& Hebrew University 2018 (Hebrew). At: https://machon.org.il/ wp-content/uploads/2019/07/d7a0d799d7a6d794-d7a7d79cd7 99d7a0d7a8-d7a7d7a1d799d7a8-d795d7a2d7a8d79f-d799d7ad7 99d791-d79bd79cd79bd79cd7aa-d794d797d791d7a8d794-d794. pdf. Retrieved May 2021.

34. Daoud N, Soskolne V, Manor O. Educational inequalities in selfrated health within the Arab minority in Israel: explanatory factors. Eur J Public Health. 2009;19(5):477-83. https://doi.org/10. 1093/eurpub/ckp080.

35. Gesser-Edelsburg A, Hijazi R. When politics meets pandemic: how Prime Minister Netanyahu and a small team communicated health and risk information to the Israeli public during the early stages of COVID-19. Risk Manag Healthc Policy. 2020;13:29853002 At: https://doi.org/10.2147/RMHP.S280952. Retrieved March 2021

36. Moscadelli A, Albora G, Biamonte MA, Giorgetti D, Innocenzio M, Paoli S, Lorini C, Bonanni P, Bonaccorsi G. Fake news and Covid-19 in Italy: results of a quantitative observational study. Int J Environ Res Public Health. 2020;17(16):5850. https://doi.org/ 10.3390/ijerph17165850.

37. Basis F, Zeidani H, Hussein K, Hareli S. Drastic reduction inpatient visits to the Emergency Department in a Hospital in Israel during the COVID-19 outbreak, compared to the H1N1 2009. Int J Health Policy Manag. 2020. https://doi.org/10.34172/ijhpm.2020. 151.

38. Guidry J, Laestadius LI, Vraga EK, Miller CA, Perrin PB, Burton CW, Ryan M, Fuemmeler BF, Carlyle KE. Willingness to get the COVID-19 vaccine with and without emergency use authorization. Am J Infect Control. 2021;49(2):137-42. https://doi.org/10. 1016/j.ajic.2020.11.018.

39. Trogen B, Caplan A. Risk compensation and COVID-19 vaccines. Ann Intern Med. 2021;2:M20-8251. https://doi.org/10. 7326/M20-8251.

40. Badre D. How we can deal with 'pandemic fatigue'. Scientific Amerecan J. Jan 24, 202. At: https://www.scientificamerican.com/ article/how-we-can-deal-with-pandemic-fatigue/ . Retrieved April 2021.

Publisher's Note Springer Nature remains neutral with regard to jurisdictional claims in published maps and institutional affiliations. 